\title{
Coda: críticas no tan veladas
}

\section{A Final Coda: Not so Veiled Criticism}

\author{
Mimunt Hamido Yahia
}

Recibido: 03-02-19

Aprobado: 19-02-19

\section{Resumen}

Es un error buscar en la religión la justificación para la igualdad entre mujeres y hombres. Estos intentos ya se dieron en los años 70 en Argelia, Marruecos y Túnez. Los tres países árabes donde el pensamiento reformista tuvo más representantes y mayor impacto. Numerosas asociaciones feministas reclamaron el derecho de las mujeres al acceso a la esfera pública y exigieron la derogación de las leyes más discriminatorias, como el repudio o la poligamia. Para dotarse de mayor legitimidad en países que mantenían el islam como religión del Estado, el feminismo laico dejó de lado su universalismo y buscó aliarse con la religión, intentando encontrar elementos feministas en el Corán, tal y como explica la abogada argelina Wassyla Tamzali. Sin dejar de poner el foco sobre el trabajo y la condición de las mujeres para mostrar la desigualdad existente, aseguraba que los ideales de igualdad eran plenamente compatibles con las Escrituras sagradas.

Palabras-clave: Feminismo, Feminismo islámico, Asociacionismo, Religión y Sociedad.

\begin{abstract}
It is a mistake to seek in religion the justification for equality between women and men. These attempts were made in the 70s in Algeria, Morocco and Tunisia. The three Arab countries where the reformist ones and had more representatives and greater impact. Numerous feminist associations claimed the right of women to access the public sphere and demanded the repeal of the most discriminatory laws, such as repudiation or polygamy. To gain greater legitimacy in countries that maintained Islam as a state religion, secular

\footnotetext{
${ }^{1}$ (shucram2@hotmail.com). Colaboradora de numerosas revistas y medios de comunicación, en la actualidad está vinculada al proyecto Mediterráneo Sur, con el que trabaja desde Estambul.
} 
feminism put aside its universalism and sought to partner with religion, trying to find feminist elements in the Qur'an, as in the explanation offered by the Algerian lawyer Wassyla Tamzali.

Key-words: Feminism, Islamic Feminism, Associations, Religion and Society.

El nueve de noviembre de 2018 andaba yo ojeando las candidaturas al Parlamento Europeo del partido Podemos, al que me siento - o sentía - cercana. Mirando la lista me sorprendió ver a una chica con hiyab de color negro que miraba sonriente a la cámara. Busqué información sobre ella y su candidatura. Se llama Nora Baños. No es para mi sorprendente que una chica musulmana con hiyab se presente a unas elecciones en España, lo que si me sorprendió es que se presentase por un partido de izquierdas que se declara laico y que además la candidata dijese en su anuncio de candidatura que se presentaba a las elecciones del Parlamento Europeo donde defendería la diversidad, la multicuturalidad y el feminismo.

Fue esto último lo que hizo que desde nuestro blog No Nos Taparán (nonostaparan.org), escribiese una carta abierta a Podemos, molesta por entender que ni la cúpula ni los militantes de este partido se hubiesen parado a reflexionar sobre lo que significa que una mujer con hiyab se presente a esas elecciones y nos hable de defender el feminismo. Ya sabía que esta carta tendría comentarios adversos, pero no sabía que tantos, tan sorprendentes para mi y tan encontrados.

La primera sorpresa fue la dura reacción de elementos que se autoadscriben a la izquierda política española. Ha sido duro oír y leer cómo desde la izquierda a las musulmanas laicas se nos trata de expulsar hacia la derecha, como han tratado hacer con otras conocidas laicistas de origen musulmán como Zineb El Rhazoui en Francia o Ayaan Hirsi Ali en Holanda. A ellas y a nosotras, la izquierda progresista no nos da espacio. Es más, nos enseñanla puerta de salida, perdiendo las mejores influencias en pos de una idea equivocada de respeto a lo diferente.

La reacción negativa del llamado feminismo islámico, muy activo en España y sobre todo en Cataluña, no fue ninguna sorpresa. En ese sector vieron esta carta como una agresión racista e islamófoba, y poco importaba que la critica viniera de una musulmana o no: cualquier crítica al islam y a sus dogmas se tacha de islamófoba. Algo curioso si atendemos a que el feminismo islámico pretende reivindicar el papel de las mujeres en el islam. Dice abogar por la igualdad completa de todos los musulmanes, sin importar su sexo, pero eso sí, todo en un contexto islámico. Cabe preguntarse como conseguir esto si no hay espacio para la autocrítica.

El feminismo islámico dice: Somos musulmanas, respetamos el islam y en el islam está la igualdad, el islam es igualitario. Sus defensoras investigan 
las escrituras, pero en cuanto se les pregunta sobre el asunto de la herencia o la poligamia resulta que no cuestionan esas normas. Ante la igualdad ponen una barrera: las normas del islam que para ellas son incuestionables. Y a mi modo de ver, esa barrera entra en seria disputa con lo que significa el feminismo.

El primer congreso internacional sobre feminismo islámico fue organizado en Barcelona, el 25 de octubre del 2005, de la mano de la Junta Islámica Catalana. Allí se debatió sobre la necesidad de un islam pluralista e igualitario. El debate fue conducido por una masa crítica de mujeres musulmanas, en su mayoría conversas. Y como conversas en disposición de actuar, no es casualidad que este movimiento que se llama feminista aglutine principalmente a conversas y mujeres musulmanas nacidas o criadas en Occidente. Todo tiene que ver con este nuevo islam europeo que ellas declaran igualitario y feminista, algunas veces argumentado con nuevas lecturas e interpretaciones del Corán.

Porque dentro de este llamado "feminismo islámico" se ven claramente dos posturas que aunque contrapuestas son a la postre totalmente iguales. La primera es la de las feministas islámicas que no se cansan de repetirnos que el Corán es igualitario, y cuando se encuentran con cuestiones como la herencia o la poligamia no lo cuestionan, simplemente se aferran a que son prácticas en desuso, ya que el feminismo islámico es europeo y aquí la poligamia y la herencia son un tema legal que ya está regulado por las leyes europeas. Evitan reconocer que las dos cuestiones son asunto de legalidad y no simples prácticas en los países musulmanes.

La otra es la postura es la de ciertos estudiosos (en general conversos) que se remontan al glorioso pasado islámico donde las costumbres eran más relajadas. Contextualizando suras o hadices tratan de acomodarlos a los nuevos tiempos, pero estas reflexiones (porque eso es lo que son) ni están muy publicitadas, ni se discuten públicamente porque... ¿ ¿cómo explicar que una sura que dice que la mujer debe heredar la mitad que su hermano no es válida hoy día y a la vez poder seguir vendiendo sin pudor laca de uñas o huevos halal? (El Instituto Halal en España está dirigido por conversas y obviamente basa su influencia en tener un mercado cautivo de musulmanes preocupados por seguir estrictamente los dogmas coránicos).

Nosotras creemos que es un error buscar en la religión la justificación para la igualdad entre mujeres y hombres. Estos intentos ya se dieron en los años 70 en Argelia, Marruecos y Túnez. Los tres países árabes donde el pensamiento reformista tuvo más representantes y mayor impacto. Numerosas asociaciones femenistas reclamaron el derecho de las mujeres al acceso a la esfera pública y exigieron la derogación de las leyes más discriminatorias, como el repudio o la poligamia. Para dotarse de mayor legitimidad en países que mantenían el islam como religión del Estado, el feminismo laico dejó de lado su universalismo y buscó aliarse con la religión, intentando encontrar elementos feministas en el 
Coran, tal y como explica la abogada argelina Wassyla Tamzali. Sin dejar de poner el foco sobre el trabajo y la condición de las mujeres para mostrar la desigualdad existente, aseguraba que los ideales de igualdad eran plenamente compatibles con las Escrituras sagradas.

Estas feministas hicieron un enorme trabajo, ganando para la causa a pensadores, intelectuales, teólogos...y fracasaron. Fracasaron porque intentaban demostrar al pueblo que la igualdad estaba en el Corán, con lo cual admitieron que el Corán era y debía ser la base para organizar una sociedad. Que el verso era lo que tenía validez sobre cualquier otra consideración. Y eso era pasarle el testigo a los islamistas que precisamente pensaban lo mismo pero aportando su propia interpretación completamente patriarcal, que es la que se está imponiendo hoy cada vez más.

La conclusión de ese intento de los años 70 es que si no se pone en tela de juicio que un libro santo pueda tener fuerza de ley, siempre habrá alguien más poderoso y mejor financiado para interpretar ese libro santo.

Ese aspecto es evidente en las feministas islámicas que usan el velo y es precisamente ese gesto el que da por válida la interpretación patriarcal que considera el velo un mandamiento islámico. Dicen rebelarse contra el patriarcado en la cultura islámica, pero ni siquiera hacen el gesto tan sencillo de cuestionar ese mandamiento patriarcal de taparse el pelo para no ofender a los hombres. Porque el velo no es un mandamiento islámico universal. Es una ideología novedosa.

En Marruecos por ejemplo el velo nos colonizó a finales de los años 80: hasta aquellos años no era corriente ver a mujeres veladas. Como dice la socióloga y periodista marroquí Sanaa El Aji: "El hiyab era una excepción en nuestro país. El mote que recibían las mujeres veladas entonces era: "la hermandad". Porque la mayoría de los colectivos sociales asociaba el hiyab a la organización de los Hermanos Musulmanes. El hiyab mostraba una afiliación política, no religiosa. Por eso, cuando algunos nos hablan de las costumbres extranjeras que nuestras sociedades han importado de fuera, recordemos que el hiyab es una costumbre ajena a nuestras sociedades, que hemos importado a través de unas ideologías beduinas que se camuflan bajo la religión para alcanzar objetivos políticos".

En el campo las mujeres lucían, por supuesto, sus pañoletas campesinas (similares a las que se usaban en las sociedades campesinas de toda Europa), pero a nadie se le ocurría pensar que taparse el pelo era un dogma ni que fuese obligatorio para ser una buena creyente. Ni se asociaba al pudor: una chica podía quitárselo perfectamente delante de cualquier hombre. El pelo no se consideraba indecente.

En las ciudades, se imitaba mucho el traje de Fes, que cubría no solo el pelo sino también parte de la cara, y se consideraba una señal de decoro para 
las mujeres de buena familia. Pero las chicas jóvenes lo fueron abandonando, sin que eso fuese considerado una falta de respeto ni una rebelión: este traje de burguesa no correspondía al concepto del hiyab, definido como un elemento necesario para preservar el pudor de una mujer frente a los hombres.

Muchas mujeres musulmanas de mi generación se preguntan ahora: ¿Que fue del islam de nuestros mayores? Con toda esta locura integrista que recorre Europa - atentados en nombre la religión, problemas de integración de los jóvenes musulmanes que ya no conocen su cultura y que son presa fácil para el integrismo, jóvenes musulmanas que creen que el hiyab es un símbolo cultural e identitario...- la gente se pregunta: ¿Cómo hemos involucionado de esta manera?

Creo que esta pregunta es fruto del desconocimiento de que, al menos en el Magreb, el islam ha formado parte de nuestras tradiciones y nuestra cultura sin estorbarlas. Nunca se han menospreciado ritos o costumbres no islámicas, porque formaban parte de nuestra cultura y no se juzgaban por su compatibilidad con los dogmas. Un ejemplo son los tatuajes, omnipresentes en todas las mujeres amazigh de cierta edad, pero que ahora se consideran, de repente, haram, es decir pecado. Hace años no pensábamos que nuestra religión pudiese ser un obstáculo para conseguir todo lo que nos propusiéramos.

$\mathrm{Si}$, había algunos dogmas inamovibles, pero según. Si no ibas a la mezquita no pasaba absolutamente nada. Guardábamos el ramadán más por costumbre que pensando en lo que significa realmente. Para los más jóvenes era como un pequeño sacrificio que conllevaba la alegría de la fiesta cada noche, te dejaban acostarte tarde e ir al paseo marítimo a reunirte con los amigos; el ritmo de la vida cambiaba un poco pero solo era eso. A nadie se le prohibía comer, nadie se sentía ofendido si comías delante de él. Las niñas no llevaban hiyab. No había obligación de rezar, eso quedaba para los muy mayores. Los vecinos cristianos y judíos venían a celebrar con nosotros y nosotros con ellos. Hoy hay quien llama "infieles" a los no musulmanes, rompiendo incluso con siglos de ortodoxia islámica que considera creyentes a cristianos y judíos.

Así que no, no hemos involucionado. Estamos yendo hacia un lugar donde antes no estuvimos.

Vemos como en Europa se quiere integrar al islam, como si el islam en este mundo globalizado perteneciera ya a una región o fuese exclusivo de países asiáticos y africanos. Olvidan un pasado donde el islam formaba parte de la cultura europea y la enriquecía. Y en lugar de aceptar que ahora podría pasar lo mismo, se equivocan integrando lo que el islam tiene de integrista. Integran corrientes salafistas o wahabíes que perjudican más a los propios musulmanes que al llamado mundo occidental. Y sobre todo nos perjudica a nosotras, las musulmanas. Lejos están ya las "primaveras árabes" donde mujeres y hombres salían juntos a manifestarse: una vez sofocadas las revueltas, las mujeres han 
vuelto a desaparecer del espacio público. Tal y como lo pretende, por todos los medios, el integrismo religioso. Da igual si se tiene que inventar un feminismo islámico para conseguirlo y seguir teniéndonos controladas. ¿Y como lo hacen? A través del velo.

Las corrientes integristas islámicas de este siglo ha estandarizado un tipo de vestimenta el hiyab. Un concepto que no forma parte, ni mucho menos, de las muy diversas sociedades musulmanas que han existido a lo largo de los siglos. Ni siquiera se puede argumentar que sea una norma coránica. Sabemos que la palabra árabe hiyab aparece en el Corán únicamente con el significado de 'cortina', sin referencia a una indumentaria femenina. Tal y como explica la revista M'Sur, 'los dos pasajes del texto que detallan explícitamente las normas del atuendo femenino distan de ser exactas en este punto, aunque numerosos exégetas las usan como fundamento para construir una supuesta obligación de ocultar el cabello". La sura Las Mujeres [24, 30-31] dice que las mujeres deben "dirigir la mirada hacia el suelo y resguardar su vulva", además de "no mostrar sus encantos, excepto los visibles". Solo una interpretación posterior, alcanzada por consenso de los teólogos, no por inspiración divina, ha definido qué son "los encantos" de una mujer y cuáles son habitualmente "visibles", a saber, nada salvo la cara, las manos y los pies (la interpretación habría sido muy distinta de alcanzarse el consenso en una ciudad costera andaluza del siglo XXI). Otra línea se interpreta como un mandamiento de "cubrir el seno con el velo”, pero “las palabras clave 'velo' (jimar) y 'seno' (yib) son de significado oscuro y la traducción ofrecida es una mera solución de consenso, no un significado obvio", subraya M'Sur. En todo caso, el mandamiento explícito de cubrirse la vulva hace pensar que quizás "los encantos visibles" en la época preislámica fuesen unos cuantos...

Pero todo este debate teológico no debe preocuparnos. Porque el error está en asumir que la teología debería marcar y determinar cada momento de nuestras vidas. No lo hace, no lo ha hecho nunca, en ningún ámbito... pero se pretende de repente ahora, cuando se trata de nuestro cuerpo, de nuestro pelo. De repente no se puede ser musulmana con la melena al aire. Y cómo pregunta la ya mencionada Sanaa El Aji: ¿Es que nuestras madres no eran musulmanas?

Se llega cada vez más lejos. En Facebook ya abundan las fotos no solo de niñas de cuatro o cinco años sino incluso de bebés casi recién nacidos... con el hiyab puesto. Eso en sí es una aberración porque la justificación teológica del hiyab está muy clara: ocultar los encantos de la mujer al hombre, es decir al varón susceptible de excitarse con estos encantos, de perder el control y de asaltar sexualmente a la mujer (por eso se puede quitar ante personas que o bien tienen derecho sexual sobre la mujer - el marido - o bien por definición no pueden tenerlo: hermanos, padre, hijos, cualquier niño antes de la pubertad). 
Al ponérsele a una niña pequeña, se está dando a entender que esta niña tiene "encantos" sexuales que debe ocultar a los hombres.

Tampoco es verdad que el hiyab "simplemente es un trozo de tela", como tantas veces se escucha. Si lo fuera, cualquier mujer podría quitárselo. Su importancia reside precisamente en que no puede quitárselo (salvo en familia o cuando solo haya mujeres delante). Es su razón de ser. Por eso hay mujeres que prefieren recurrir al Tribunal de Estrasburgo antes de pasar por el aro de aceptar un trabajo en el que les obliguen a trabajar sin ese "trozo de tela". (El Tribunal ha dado la razón a las empresas que vetan el hiyab, al no poder acreditarse que ese "trozo de tela" sea una condición religiosa ineludible de toda musulmana).

El hiyab es una declaración de intenciones que va mucho más allá del pelo. La oleada salafista que vivimos en el norte de Marruecos no solo ha contribuido a poblar las calles con pañuelos y desterrar el bikini de las playas, también ha traído otros cambios. En mi familia siempre comían mujeres y hombres juntos, tanto en lo cotidiano como en las fiestas de guardar. De unos años a esta parte observo que mujeres relacionadas con mi familia - todas ellas correctamente hiyabizadas - insisten en que hombres y mujeres coman por separado en las celebraciones. Y por supuesto, que a ellos se les debe servir antes que a ellas.

Dirán las conversas que a ellas, el hiyab no les obliga a nada. Podrán decirlo, porque viven en un entorno que no les obliga a nada, y podrán aducir que si no van a la playa es porque les molesta el sol. Pero no es la realidad de la comunidad musulmana en España, compuesta en gran parte por marroquíes de segunda generación. Para muchas de ellas, llevar hiyab sí es una obligación que viene junto y se rompe junto a toda una serie de normas: no consumir alcohol, no salir con chicos, no tener novio "cristiano" (es decir, no musulmán) y, por supuesto, guardarse virgen hasta el matrimonio. Me podrán decir mucho, pero feminismo no es.

Es precisamente este debate que se intenta evitar a toda costa desde la izquierda. Cuando escribí mi carta abierta a Podemos, numerosas voces me recriminaron que atacara a una mujer, y además una mujer de una minoría. La propia candidata lamentaba "los ataques recibidos" pero evitaba en todo momento posicionarse respecto al significado de esa prenda negra que le cubría pelo y escote. Porque este es el dilema de la izquierda que defiende el hiyab como "diversidad": si admitiera que se trata de un signo religioso fundamentalista, se desacreditaría totalmente; si asegurase que no tiene una connotación dogmática religiosa, no podría justificar la negativa a quitárselo antes los hombres, ni podría alinearse con quienes, en consonancia con los dogmas ultra, exigen horarios separados en las piscinas y apoyan el uso del burkini en las playas.

Ante este dilema, muchas defensoras en la izquierda reivindican la "libre decisión" de las mujeres a ponerse "lo que quieren", sin que nadie venga decirles 
qué tienen que ponerse. Pero cierran los ojos ante el hecho de que llevar el hiyab es precisamente seguir las órdenes de los teólogos fundamentalistas que sí dicen a las mujeres qué deben ponerse, y que para millones de mujeres en el mundo, el hiyab no es una elección, sino una imposición, por ley en algunos países, por presión social en otros. Llegados a este punto, la respuesta más habitual es decir que no hablamos de otros países, sino de España. Y yo que pensaba que la izquierda tenía vocación universal.

Mi respuesta favorita a mis críticas al velo en las redes sociales es la que afirma que el hiyab "es tan sexista como llevar tacones o minifalda". Como si hubiera países con leyes que castigaran a las mujeres que no llevaran minifalda, como si existieran familias en las que se les prohibiera a las hijas salir a la calle con sandalias o en vaqueros.

Abundan incluso, tanto en España como en Europa, las iniciativas del "día del hiyab" como respuesta a las discriminaciones que puede sufrir una mujer velada en nuestra sociedad, animando a las mujeres no musulmanas de "ponérselo para un día" para "ponerse en su piel" y postear una foto velada en las redes sociales en señal de solidaridad. Lo que todavía no he llegado a ver es un "día del no hiyab" en el que se anime a las mujeres que sí lo llevan quítarselo un día y postear una foto en solidaridad con las mujeres obligadas a llevarlo, sea en otros países, sea en nuestro propio país en los guetos de la inmigración. Eso no. Parece ser que la libertad, en opinión de esta izquierda, es unidireccional: ponérselo, sí. Quitárselo, nunca.

Eso no es defender la libertad. Eso es defender una ideología religiosa.

En nuestros días el hiyab es, escencialmente, el uniforme de un movimiento político que considera que la religión es la base de la lucha social. Y sobre todo en Europa tiene un sentido político clarísimo. Disfrazarlo de moda o de libre elección, incluso de prenda empoderante y feminista es muy peligroso para el movimiento feminista laico. Han conseguido que las jóvenes musulmanas crean que es una obligación llevar puesto un símbolo identitario (ahora lo llaman así) y sexista para sentirse parte de algo.

Al cerrarse a este debate, la izquierda está expulsando a las feministas laicas del entorno musulmán hacia la derecha, que recoge encantada nuestros argumentos para demostrar que "el islam" es sexista e "incompatible con los valores europeos". No lo es más que la religión cristiana, y no se trata de "valores europeos" sino universales: lo demuestra una larga tradición feminista, de lucha por la igualdad entre mujeres y hombres, en los propios países musulmanes. Una lucha que ahora se silencia para dar a entender que no existe un islam sin segregación de sexos. Algo que no es verdad, como sabemos bien las que hemos nacido en un entorno musulmán, pero que viene muy bien a la derecha para articular un discurso xenófobo y contrario a la inmigración. La diferencia es que en Europa hemos aprendido hacer frente al discurso fundamentalista cristiano, pero nos entregamos 
al discurso fundamentalista islámico como si fuese la expresión genuina del sentir de cientos de millones de musulmanas, y no su opresor.

El peligro aquí es no poder separar religión, política y cultura, y se trata justamente de eso: si en Europa no lo han entendido aún no será porque en los países musulmanes no existan voces que a pesar de la represión tienen que ser oídas. Como bien dice Zineb El Rhazoui a los defensores del velo: "Al tomar partido por el ala fascista del islam, arrojas a sus fauces a los demás, a la mayoría silenciosa y a la minoría laica militante".

Es un mundo ya globalizado, el islam no puede tener su Brexit particular. Las musulmanas tenemos que ser las impulsoras del cambio. No podemos ser solo la bastión de la religión en Occidente. Nos han dado el papel de guardianas del honor, de las costumbres, la lengua y la tradición, y somos su símbolo visible. Nosotras decimos que tenemos honor, el nuestro, y no está entre nuestras piernas ni en nuestro pelo. Somos musulmanas, pero no consentiremos que nadie nos imponga dogmas religiosos o políticos disfrazados de "cultura".

Separar cultura y religión es nuestro trabajo, y sobre todo enseñar igualdad. Solo así el mundo musulmán puede salvarse de si mismo. 
